Наталия Нягалова ${ }^{1}$

Кафедра славянской филологии, Великотырновский университет, им «Святых Кирилла и Мефодия»

Великое Тырново

\title{
КАБИНЕТ СТАВРОГИНА В ЛИТЕРАТУРЕ И В КИНО: ПРЕДВАРИТЕЛЬНЫЕ ЗАМЕЧАНИЯ
}

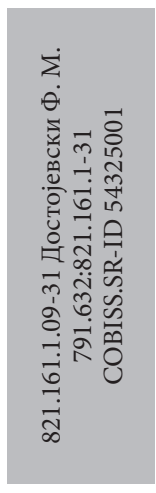

\begin{abstract}
Аннотация
В статье анализируется семантика локуса кабинета Николая Ставрогина в романе Ф. М. Достоевского Бесы. Прослеживается предметный состав, приниипы его отбора и механизмы, в которых данный пространственный элемент участвует при построении сюжета. Обозначается роль кабинета в поэтике Достоевского как единой системы. Исследуются трансформации локуса в существующих экранизачиях произведения.

Ключевые слова

поэтика, локус, роман, экранизация, знак, персонаж, Ставрогин
\end{abstract}

\section{Кабинет в романной топографии Достоевского}

По мнению М. Бахтина, хронотоп пронизывает каждый элемент, каждый мотив художественного текста (Бахтин 1975: 404). Также по его мнению: «У Достоевского на улицах и в массовых сценах внутри домов (преимущественно в гостиных) как бы оживает и просвечивает древняя карнавально-мистерийная площадь. Этим, конечно, еще не исчерпываются хронотопы у Достоевского: они сложны и многообразны» (Бахтин 1975: 405)

Для героев русского классика ансамблевые сцены - лишь мгновения трагедии, страшной работы совести, превращения теорий и наваждений в поступки. Для его героев существование - это аккумуляция, на-

1 nniagalova@gmail.com 
копление, созревание их фикс-идей. Они рождаются и крепнут в одиночестве, в отчуждении, в отделении от мира, и им нужно собственное пространство, которое может их приютить и выразить - подполье, келья, коробка, гроб, конура, футляр...

Таким образом, в романном пространстве у Достоевского можно вывести последовательную контрастную организацию - «карнавальные» массовые локусы (гостиная, площадь, улица, зал, парк, игровой дом) и индивидуальные, замкнутые поля идей (комната, кабинет, угол).

Голландский исследователь Иост ван Баак утверждает, что в русской литературе дом всегда одушевлен (Baak 2009: 127), что говорит о тесном отождествлении между героем и материальным миром. Помещение кабинета оказывается частью быта русского дворянства под влиянием культуры Просвещения, для которой личная жизнь человека имеет особый приоритет. Следуя логике Баака, можно утверждать, что в русском романе первой половины XIX века кабинет является проекцией человеческого сердца и его тайн ${ }^{2}$, а в его интерьере нередко скрывается ключ к разгадке таинственного центрального персонажа. В послереформенный период, в соответствии с динамичным социально-историческим контекстом, усложняются также отношения героя и пространственно-временного окружения, что приводит к кардинальным изменениям в хронотопической «ценности» кабинета.

Объектом исследования настоящей работы является семантика кабинета Николая Всеволодовича Ставрогина в романе «Бесы» и ее интерпретация в экранизациях произведения. Предлагаемые в ней наблюдения носят предварительный характер и представляют собой структуру будущего, детального изучения проблемы.

В черновых заметках к роману Достоевский пишет: «Князь (Ставрогин) - все». Остальные персонажи - это функции сознания Ставрогина, распадающегося на многочисленные противоречия и борющегося с многообразными искушениями (Мочульский 1980: 354). Различные «лица» героя-загадки имеют и свои пространственные проекции. В путешествии Ставрогина в Исландию и его женитьбе на Марье Лебядкиной исследователи видят попытку реализовать «рыцарски благородного»

2 В «Княгине Лиговской» М.Ю. Лермонтов пишет: «Один только кабинет иногда может разоблачить домашние тайны, но кабинет так же непроницаем для посторонних посетителей, как сердце [...]» (Лермонтов 1957: 149) 
героя (Смирнов 2001: 29) «Принц Гарри» подвизается в традиционном для русской культуры городе зла - Петербурге. «Иван-царевич, самозванец» возвращается в родной губернский город $\mathrm{N}$, провинциальные скандалы которого оборачиваются тотальными социальными катастрофами. В комнатке Марьи Тимофеевны Ставрогин мифологически «множится» на противоположные образы - сказочного князя и ясного сокола, «сыча», «купчишку», Гришку Отрепьева. ${ }^{3}$

В контрастной романной топографии кабинет представляет собой пространственный эквивалент подсознания героя, своего рода синоним подполья в поэтике писателя, которое опредмечивает собой «мироощущение персонажа, характеризуясь загнанностью, стремлением спуститься вниз, укрыться от “живой жизни” (Лескова 2014: 69). В этой своей функции локус кабинета проявляет себя уже в «Идиоте». Впервые характеристики обиталища инфернального героя приобретает кабинет Парфена Рогожина. Помещение связывается с темнотой, а среди его бесцветной обстановки располагается «красный, широкий, сафьянный диван», и он, как кровавое пятно в интерьере, становится предметом-предчувствием грядущего преступления (в постели Рогожина будет лежать мертвая Настасья Филипповна). Психическое состояние Парфена Семеновича после убийства отражено в изменении кабинетного интерьера: «Вошли в кабинет. В этой комнате, с тех пор как был в ней князь, произошла некоторая перемена: через всю комнату протянута была зеленая, штофная, шелковая занавеска, с двумя входами по обоим концам, и отделяла от кабинета альков, в котором устроена была постель Рогожина» (Достоевский 1989: 606). Разделение пространства кабинета соответствует амбивалентности поведения (жертвы и убийцы) и сознания (сознательное-бессознательное) персонажа. Задействован мифологический потенциал завесы, восходящий к сакральной завесе храма, а также такие значения, как «препятствие», «ослепление», «безверие», формирующие представление о непреодолимом одиночестве и таинственном драматизме героя.

3 Все эти воплощения комментируются в исследовании Вячеслава Иванова „Экскурс. Основной миф в романе «Бесы» от 1914 г. (Иванов 1987: 441) 


\section{Кабинет Ставрогина в «Бесах»- предметный состав и фабульные функции}

В таком же мрачном, «тенистом» кабинете будет обитать и Николай Всеволодович: «Было семь часов вечера. Николай Всеволодович сидел один в своем кабинете, - комнате им еще прежде излюбленной, высокой, устланной коврами, уставленной несколько тяжелою, старинного фасона мебелью. Он сидел в углу на диване, одетый как бы для выхода, но, казалось, никуда не собирался. На столе пред ним стояла лампа с абажуром. Бока и углы большой комнаты оставались в тени». (Достоевский 1990: 207)

Комната как бы лишена интерьера (скупо упомянуты только ковры и мебель старого фасона). Подробно описано освещение - «лампа с абажуром», «темные бока и углы комнаты». Кабинет в «Бесах» компактный, недетализированый, но его описание создает ощущение переполненности за счет скопления однородных частей - «излюбленная», «высокая», «устланная», «уставленная», «тяжелая», «старинный». Он становится пространством внутренней борьбы Ставрогина. Лишь в своем мрачном кабинете и в келье монаха Тихона он заговорит о своих воображаемых и реальных «бесах»: «Один бесенок предлагал мне вчера на мосту зарезать Лебядкина и Марью Тимофевну, чтобы порешить с моим законным браком, и концы чтобы в воду. Задатку просил три целковых, но дал ясно знать, что вся операция стоить будет не меньше как полторы тысячи. Вот это так расчетливый бес! Бухгалтер!» (Достоевский 1990: 277); «Так как я прибавил сейчас эту... фразу, то вы, наверно, думаете, что я все еще сомневаюсь и не уверен, что это я, а не в самом деле бес?» (Достоевский 1990: 638). Кабинет в «Бесах» становится пространством оспоренной «собственной территории» и полем постоянного нарушения каких-то сословных и психологических границ. Чаще всего в качестве «нарушителя» выступает Петруша Верховенский. Он входит без приглашения в кабинет Nikolas, по-свойски располагается на диване фон Лембке.

К себе в любимый кабинет будет удаляться Николай Ставрогин при каждом срыве и там он будет страдать от различных физических недомоганий неясного происхождения - головной боли, абсцесса, лихорадки. Это проявления той особой, отдельной, автономной жизни, которой живет тело у Ставрогина. Его экстатическая душа, изъеденная неверием и угрызениями, уничтожает это тело - красивое, сильное, порочное 
- с продуманной, злой последовательностью, «преднамеренно и сознательно до последней минуты».

\section{Кабинет и распад индивидуального пространства}

В многочисленных экранизациях романа, подчиняющихся различным режиссерским концепциям, кабинет трансформирует свой предметный состав и функции.

Михаил Ямпольский отмечает, что изображение быта тесно связано с проблемой языковой природы кино (Ямполски 2014: 277-278). Вещи в фильме, их отбор, план изображения и сочетаемость, свидетельствуют о том семиотическом механизме, посредством которого предмет на экране участвует в преобразовании движущихся кадров в целостный кинотекст. Когда речь идет об экранизации, изучение этого механизма также предполагает анализ отношения между исходным литературным текстом и его киноверсией в свете тех изменений, которые режиссер вносит в оригинал. Эти изменения значимы и отражают основную постановочную концепцию.

В первой сохранившейся экранизации ${ }^{4}$ романа «Бесы» (1988) режиссера Анджея Вайды преобладание образа Ставрогина как организующего центра в структуре произведения приглушено, а на первый план выдвинут коллективный образ «бесов» - революционеров. Такая концепция понятна, если учесть время появления экранизации - конец 1980-х годов XX века - период крупнейших политических перемен в Центральной и Восточной Европе. Такой режиссер, как Вайда, особенно чувствительный к общественному контексту, не мог устоять перед искушением привнести, пусть и ненавязчиво, современные акценты в кинематографическое прочтение романа. Бит в экранизации Вайды полностью подчинен историческому колориту (Горбаневская 2004). Он призван через предметно-пространственную обстановку воспроизвести атмосферу российского провинциального города второй половины XIX века, породившего в своих недрах новых бесов. Но в поэтике Достоевского вещь используется для этой цели минимально. Вещь у Достоевского подчеркнуто символична, семиотична, проникнута особой атмосферой нового набора «роковых предметов» - прием, заро-

4 Первая экранизация романа - «Николай Ставрогин» - режиссера Якова Протозанова от 1915 года не сохранилась. 
дившийся еще в поэтике романтизма. Вайда нарушает драматическую связь между предметом и персонажем у Достоевского, сводя материальную среду романа к театральной декорации, подчиненной сюжету и визуализирующей исторически достоверный хронотоп. Этот тип режиссерского подхода иллюстрирует концепцию А.П. Чудакова о предметности у Достоевского, которую исследователь рассматривает как обслуживающую «высшие сферы» (Чудаков 1980: 105) Связь «предмет - персонаж» у Достоевского - это связь не иерархичности, а проникновения, симбиоза, врастания. В романах писателя «вещи и вещества наравне с людьми становятся героями текста: возникает то, что можно назвать эмблематическим сюжетом или онтологической схемой произведения» (Карасев 1994: 90). Из визуализации кабинета Ставрогина Вайда удалил специфику помещения как индивидуального обиталища героя. Логовище Человекобога не нужно его концепции, представляющей «бесовство» как коллективную болезнь. Комната, в которой обитает Николай Ставрогин, у Вайды намного больше похожа на гостиную. При этом нарушена важная характеристика локуса в романе - его полуосвещенность.

Инфернальные герои Достоевского - это герои тьмы. Аркадий Иванович Свидригайлов впервые появляется «поздним вечером», когда «сумерки сгущались». Войдя в кабинет Рогожина, князь Мышкин заметит: «Мрак-то какой. Мрачно ты сидишь» (Достоевский 1989: 209). В тексте «Бесов» «мрак» и производные от него лексемы участвуют в построении самых драматических фабульных эпизодов - свидания Ставрогина с Марьей Тимофеевной, разговор с Федькой Каторжным, убийство Шатова...

\section{Кабинет и кинематографическое прочтение «православной идеи»}

В 1992 году режиссерами Игорем и Дмитрием Таланкиными была создана новая экранизация романа. Это экранизация «по мотивам», в которой доминирует линия Ставрогина. Концепция двух режиссеров также обнаруживает связь с акцентами современности - с периодом «великой переоценки» конца XX века. В отличие от Вайды, Таланкины пытаются через субъективную драму Ставрогина представить болезненные катаклизмы времени. Свой подход к тексту они определяют как желание соотнести современные социальные коллизии с «бесовщиной» 
в романе: «Достоевский - то, чем мы сегодня болеем, мучаемся, страдаем (Энциклопедия 2011). Но мир кинокартины говорит о другом: о том, что режиссеры руководствовались концепцией, характерной для постперестроечного прочтения текстов писателя - реабилитацией их православного подтекста. Наиболее ярким показателем этого является лейтмотивная для данной экранизации «символика креста» (Грачева 2004). Перед визитом Даши в кабинет Ставрогина (часть 2, глава 3, IV) он лежит «распятый» на блестящем паркетном полу. Прослеживая православную образность в тексте, режиссеры активно занялись экспериментами в плане оппозиции «тьма-свет», которая в поэтике Достоевского зачастую представляет собой связь психологического и религиозного пластов произведения. ${ }^{5}$

\section{Локус кабинета и формат телесериала}

В 2006 году была выпущена новая экранизация романа «Бесы» - в восьми сериях. Режиссеры фильма - Валерий Ахадов и Геннадий Карюк. К началу XXI века российская киноиндустрия открыла для текстов Достоевского формат телевизионного сериала. Сериальные постановки по Достоевскому делались и раньше, но их структура больше соответствует тому, что в терминологии советских телевизионных жанров называется «многосерийным телефильмом» (Зоркая 1976: 24). Сериал В. Бортко «Идиот» (2003) ознаменовал начало свободного применения классического мелодраматического инструментария сериала, отвечающего требованиям популярной культуры, к текстам Достоевского. О концепции Ахадова и Карюка многое говорит факт съемки продукции в павильонных условиях. Эта искомая «искусственность» предметно-пространственной среды создает эффект театральности. Еще Константин Мочульский определил роман «Бесы» как «театр трагических и трагикомических масок». Лицо «гражданина кантона Ури» в тексте неоднократно сравнивается с маской. «Маска в романе становится проводником бесовских сил» (Мочульский 1995: 57). В экранизации Ахадова и Карюка встреча Ставрогина с Маврикием Николаевичем (часть 2, глава 6, VII) представлена в кабинете героя. Интерьер помещения вы-

5 Об этой связи говорится практически во всех существующих исследованиях на эту тему. В частности, можно упомянуть две диссертации последних десятилетий: Панкратова М.Н. Поэтика света и тьмы в творчестве Ф.М. Достоевского, М., 2007 и Азаренко Н.А. Концептуализация света и тьмы в языковой картине мира Ф. М. Достоевского, Липецк, 2007 
держан в подчеркнуто зеленой гамме. В поэтике романа такое цветовое решение имеет свои основания. Произведение буквально пронизано, захвачено этим цветом. Чаще всего «зеленеют» персонажи (Ставрогин, Петруша, Гаганов, Варвара Петровна, Юлия Михайловна). Зеленым цветом обозначена комнатка начинающего чиновника, русского немца фон Лембке: «Но вместо богатств, которые посетитель ожидал встретить, он нашел своего “Лембку” в боковой очень маленькой комнатке, имевшей темный и ветхий вид, разгороженной на двое большою темно-зеленою занавесью, меблированной хоть и мягкою, но очень ветхою темно-зеленою мебелью, с темно-зелеными сторами на узких и высоких окнах.» [курсив наш - НН] (Достоевский 1990: 293). Длинной зеленой занавесью разделена и комната Марьи Тимофеевны. ${ }^{6}$

Колорит в романах Достоевского является предметом изучения с начала XX века, но о систематических выводах в плане функций цвета в текстах писателя пока говорить нельзя. ${ }^{7}$ Зеленый - один из самых распространенных цветов в цветовой гамме Пятикнижия ${ }^{8}$. Он связывается с разнонаправленными интерпретациями. Е. Степанян-Румянцева рассматривает ситуации, содержащие обозначение зеленого цвета в романах Достоевского, как свидетельство того, как «быт, равнинное течение жизни может переходить и в состояния тупиковые, зловещие, чреватые страшным исходом, и в состояния, дающие человеку внутренний подъем и надежду» (Степанян-Румянцева 2011: 319). Такое объяснение не дает четких критериев для определения функции данного цвета. По мнению Т. Касаткиной, «зеленый цвет у Достоевского почти всегда связан с символикой Богородицы, Заступницы перед Богом за землю» (Касаткина 2004: 212) Но в текстах есть много случаев, когда предлагаемая связь «не работает», а и было бы слишком максималистски объяснять ею столь разное по своей природе использование этого цвета - от зеленой церкви во сне Раскольникова, через драдедамовый платок

6 «Комната Марьи Тимофеевны была вдвое более той, которую занимал капитан, и меблирована такою же топорною мебелью; но стол пред диваном был накрыт цветною нарядною скатертью; на нем горела лампа; по всему полу был разостлан прекрасный ковер; кровать была отделена длинною, во всю комнату, зеленою занавесью, и, кроме того, у стола находилось одно большое мягкое кресло, в которое, однако, Марья Тимофеевна не садилась.» (Достоевский 1990: 258).

7 Цветообозначениям у Достоевского посвящено огромное число работ. В библиографии к диссертации Степановой Е.В. «Колористическое искусство прозы Ф.М. Достоевского 1860-х годов», Саратов. Саратовский гос. университет, 2010, приводится подробный список исследований.

8 Принятое в критической литературе общее название для пяти основных романов писателя: «Преступление и наказание», «Идиот», «Бесы», «Подросток» и «Братья Карамазовы». 
Сони, и до зелено-красного шарфа Рогожина. В. Кантор связывает появление зеленого цвета в «Преступлении и наказании» с «отсутствием истинных человеческих отношений в мире» (Кантор 2008), подкрепляя свое утверждение лишь одним примером из текста. Схожим образом, на наш взгляд, можно интерпретировать использование зеленого цвета в поэтике «Бесов». Ключ к тотальному «позеленению» в романе дает диалог Петруши и Ставрогина:

«- Однако прощайте, вы какой-то зеленый.

- Лихорадка у меня.» (Достоевский 1990: 215).

В тексте «Бесов» различные названия лихорадочного состояния - «лихорадка», «горячка» - являются одними из самых частотных лексем. В романе зеленый цвет охватывает как предметный мир, так и лица персонажей. И в том, и в другом случае это цвет хаоса, болезни, бесовской лихорадки, в которой существуют герои Достоевского.

Кабинет в экранизации Ахадова и Карюка приобретает функции объединяющего, узнаваемого локуса - напрямую связанного с поэтикой сериала, основывающейся на инновации и повторении. (Эко 1997: 56-57) Цвет служит узнаваемости топоса, его воспроизводимости в различных фабульных ситуациях.

\section{Кабинет и энтомологическая символика в творчестве Достоевского}

В 2014 году был создан сериал «Бесы» в постановке известного российского режиссера Владимира Хотиненко. В сериале Хотиненко кабинет сильно меняет свой предметный состав. «Кабинетные» кадры заполняет огромный стол, на котором размещены витрины с засушенными бабочками, склянки с формалином и микроскоп. Эти естественно-научные атрибуты идут вперемежку с кучей картин с изображениями ангелов и демонов. Сидящий за этим столом Ставрогин напоминает одновременно и естествоиспытателя, и Пьеро эпохи модерн - страдающего и насмешливого (Молодцова 1990: 136-137). Топос представлен в сериале в двух вариантах - «светлом» (полном солнца и воздушности) и «темном» (в кошмарах Ставрогина). Кабинет в сериале Хотиненко - это пространство, наполненное мифологическими образами. В его «светлом» варианте у стола Ставрогина неизменно стоит его трость - 
один из предметов-героев экранизации, набалдашник которой с выгравированной головой змеи будет неоднократно появляться в кадре крупным планом. Это изображение отсылает к названию главы «Премудрый змий» романа, в которой Ставрогин и Петруша Верховенский появляются в городе 9 . В «темном» варианте кабинета разыгрываются видения его обитателя, представляющие собой превращение пойманных бабочек в чудовищ.

Кабинет становится частью концепции режиссера о красоте, которая становится «знаком смерти для увидевшего ее воочию», и своеобразным пространственно-предметным эквивалентом психологического мира героя - внешне изящно-обаятельного и внутренне инфернально-демонического. Знаком этой амбивалентности становится лейтмотивный для сериала образ бабочки - «ничтожной твари, которой дана удивительно щедрая форма». Именно к этому образу возникли основные претензии со стороны кинокритики ${ }^{10}$. Практически незамеченными остались куда более несовместимые с романным миром «Бесов» «вольности» режиссера - грубо «смонтированный» в повествовании следователь Горемыкин и безвкусный даже для такого массового формата, каким является сериал, «швейцарский» финал. ${ }^{11}$

Локус кабинета в литературе второй половины XIX века включает в свою семантику связь с энтомологической символикой. Появляется образ «паука в паутине», выражающий связь между кабинетом и его обитателем (Мопассан 1974). Образ бабочки, созданный Владимиром Хотиненко в сериале «Бесы», дополняет развернутую метафорическую цепочку «паук - клоп - муха», заданную в романном оригинале, вокруг которой объединяются Ставрогин, Лебядкин, Лиза, Кириллов. Энтомологическая образность у Достоевского, как правило, коннотируется

9 Здесь интерпретацию можно продолжить в сторону мифопоэтических значений самой вещи (как варианта священного «посоха»), но это выходит за цели нашего анализа.

10 Напр., Маслова Л. «И бабочки кровавые в глазах» // Газета «Коммерсантъ», №89 от 27.05.2014, с. 15; Богомолов Ю. «А бабочка крылышками - бяк, бяк, бяк» // Киносоюз, 28. 05. 2014, http://www.kinosoyuz.com/news/?pub=2319 [Дата использования 09. 03. 2015]; Межуев Б. «Достоевский, дополненный Горьким» // «Известия», 2 июня 2014, http:// izvestia.ru/news/571844 [Дата использования 08. 03. 2015].

11 Именно образ бабочки, как ведущий образ в сериале, по нашему мнению, полностью обоснован с точки зрения поэтики Достоевского. Как известно, в этой поэтике присутствует сложный энтомологический метафорический ряд - достаточно вспомнить последний сон Раскольникова, бриллиантовую булавку на шарфе Рогожина, изображающую жука, сладострастное «насекомое» Федора Павловича Карамазова. 
отрицательно ${ }^{12}$. Связь образа «князя» и образа бабочки основывается не только на ее амбивалентной красоте, но и на ее физиологической способности к трансформациям. Такая метафора позиционирует Ставрогина как персонажа не только синхронно - в контексте целого ряда демонических героев Пятикнижия, но и диахронно - как типологический образ в исторической поэтике русской литературы. Образ бабочки делает Ставрогина частью эмблематического ряда, начинающегося с поэтики Пушкина (в черновиках «Пиковой дамы» Герман владеет коллекцией бабочек) и доходящего, по меньшей мере, до произведений Набокова (Шадурский 2004: 42-43).

Предлагаемые наблюдения представляют кабинет Ставрогина как элемент сложной парадигмы, отражающей различные акценты в кинематографической рецепции романа-трагедии. В семантике топоса пересекаются и наслаиваются и другие проявления образа демонического героя, которые могут стать предметом будущих исследований: проявления метафорические, идеологические и интертекстуальные. Это и кабинет русского Фауста, фатального и губительного ${ }^{13}$, это и одинокое обиталище русского Гамлета, у которого «никогда не было ни Горацио, ни Офелии», это и пространство русского Сверхчеловека, подымающегося из темноты своего логовища по «деревянной, длинной, очень узенькой и ужасно крутой лестнице», чтобы найти смерть, а не «великий гимн нового и последнего Воскресения».

\section{Литература}

- Baak, J. J. (2009) The House in Russian Literature: A Mythopoetic Exploration. Hardcover, Amsterdam-New York, Published.

- Бахтин, М. М. (1975) Формы времени и хронотопа в романе// Вопросы литературы и эстетики. М.: Худож. литература.

12 Василий Розанов пишет: «Паук - это что-то злое» (Розанов 2013: 1); Г.Г. Ермилова определяет данный образ как «символ утонченного сладострастия» (Ермилова 1998: 44); Татьяна Касаткина отождествляет паука с обескрыленной своим сладострастием душой, привязанной к земле (Касаткина 2001: 62); Дьёрдь Золтан Йожа связывает этот образ у Достоевского со значением «потусторонность», «потусторонний мир» (Józsa2004: 277).

13 Об интертекстуальной связи между образами Ставрогина и Фауста пишут также В. Иванов, Л. Бем, К. Мочульский. Из современных исследований можно отметить статью М. Хасиевой, которая рассматривает функционирование этой связи в целом ряде произведений Ф. М. Достоевского. (Хасиева 2014: 203). 
- Горбаневская, Н. (2004) Пророчество, обросшее плотью. О фильме Анджея Вайды «Бесы» // Новая Польша. 3/2004, http://www.novpol. ru/index.php?id=207. [Дата обращения: 02. 09. 2021].

- Грачева, Е. (2004) Новейшая история отечественного кино. 19862000. Кино и контекст. Т. VI. СПб.: Сеанс. 2004.

- http://2011.russiancinema.ru/index.php?e_dept_id=1\&e_person_ id=906, [Дата обращения: 04. 09. 2021].

- Достоевский, Ф. М. (1989) «Идиот» // Собрание сочинений в пятнадц,ати томах. Ленинград: «Наука» - Ленинградское отделение, т. 6.

- Достоевский, Ф. М. (1990) «Бесы» // Собрание сочинений в пятнадиати томах. Ленинград: «Наука» - Ленинградское отделение, т. 7.

- Ермилова, Г. Г. (1998) Событие падения в романе Ф.М. Достоевского «Бесы» // Вопросы онтологической поэтики. Потаенная литература. Иваново: Ивановский государственный университет. 39-57.

- Зоркая, Н. М. (1976) Чары многосерийности // Многосерийный телебильм: Истоки. Практика. Перспективы. М.: Искусство. 21-36.

- Иванов, В. (1987) Экскурс. Основной миф в романе «Бесы» // Собрание сочинений в 4 томах. Том 4, Брюссель.

- Józsa, G. Z. (2004) Трансформации мотива паука. Визуальное как трансмиттер: Достоевский - Добужинский - Набоков // Studia Russica Budapestiensia. 2004 (XXI). 276-291.

- Кантор, В. К. (2008) Платки, интерьеры, шляпы. “Вещный мир” в поэтике Достоевского // Независимая газета. 2008. 20 ноября. 12.

- Карасев, Л. В. (1994). О символах Достоевского// Вопросы философии. 1994. №10. 90-111.

- Касаткина, Т. А. (2001) Роль художественной детали и особенности функционирования слова в романе Ф. М. Достоевского «Идиот» // Роман Ф. М. Достоевского «Идиот»: Современное состояние изучения. М. 2001. 60-99.

- Касаткина, Т. А. (2004) Онтологичность слова в творчестве Ф.М. Достоевского как основа «реализма в высшем смысле». М.: ИМЛИ PAH.

- Лермонтов, М. Ю. (1957) Княгиня Лиговская // Сочинения в 6 томах. Москва-Ленинград: Изд. АН СССР, т. 6.

- Лескова, Е. В. (2014) Кафка и Достоевский: «нора», «подполье» как притчеобразующие метафоры // Вестник Челябинского государственного университета. 2014. № 16 (345). Филология. Искусствоведение. Вып. 91. 69-73.

- Молодцова, М. М. (1990) Комедия дель арте (История и современная судьба). Л.: ЛГИТМиК. 
- Мопассан, Г. (1974) Монт-Ориоль М.: Худ. литература. http://www. lib.ru/INPROZ/MOPASSAN/mopasan3.txt. [Дата обращения: 28. 08. 2021].

- Мочульский, К. В. (1995) Гоголь. Соловьев. Достоевский. М.: Республика.

- Мочульский, К. В. (1980) Достоевский: жизнь и творчество. М.: Книга по требованию.

- Розанов, В. В. (2013) Размолвка между Достоевским и Соловьевым, М.: Лань.

- Смирнов, В. А. (2001) Литература и фольклорная традиция: вопросы поэтики (архетипы «женского начала» в русской литературе XIX - начала XX века): Пушкин. Лермонтов. Достоевский. Бунин. Автореферат дисс. Иваново: Ивановский гос. университет.

- Степанян-Румянцева, Е. (2011) Изобразительный код «Идиота»// Вопросы литературы. N 5. 318-337.

- Хасиева М.А. (2014) Интертекстуальные трансформации сюжета о Фаусте в произведениях Ф. М. Достоевского // Филологические науки. Вопросы теории и практики. Тамбов: Грамота. 2014. № 2 (32): в 2-х ч. Ч. II. 200-204.

- Чудаков, А. П. (1980) Предметный мир Достоевского // Достоевский. Материалы и исследования. Л.: «Наука». т. 4. 96-105.

- Шадурский В. В. (2004) Интертекст русской классики в прозе Владимира Набокова. Великий Новгород: Новгородский университет им. Ярослава Премудрого.

- Эко, У. (1997) Инновация и повторение. Между эстетикой модерна и постмодерна // Филособия эпохи постмодерна. М., 52-74.

- Энциклопедия отечественного кино (2011), под ред. Л. Архус, http://2011.russiancinema.ru/, [Дата использования 06. 03. 2015].

- Ямполски, М. (2014) Битът като материал: безпорядъкът в Русия // Език - тяло - случай. Киното и търсенето на смисъла. С.: Пергамент. 277-294. 
Наталия Нягалова

Department of Slavic Studies,

St. Cyril and St. Methodi us University,

Veliko Trnovo

THE STUDY ROOM OF STAVROGIN IN THE LITTERATURE AND CINEMA Preliminary Remarks

\begin{abstract}
The article analyses the semantics of the topos of Nikolai Stavrogrin's study room in the novel "Demons" (Бесbl) by F.M. Dostoevsky. It examines the composition of the objects, the principles of selection of this composition and the mechanisms in which a given spatial element takes part in building up the plot. It outlines the role of the study room in the poetics of Dostoevsky as an integral system. Transformations of the topos in the existing screen adaptations of the novel are explored.
\end{abstract}

Keywords

poetics, topos, novel, sign, character, Stavrogin

Primljeno: 1.9.2021.

Prihvaćeno: 22.9.2021. 